\title{
Arranjo institucional e sistema de inovação: interação UFSC e Petrobras*
}

\author{
Paola Azevedo ${ }^{\dagger}$ \\ Silvio A. F. Cario
}

\begin{abstract}
Resumo
A interação universidade e empresa (U-E) caracteriza-se como arranjo interinstitucional importante no Sistema Nacional de Inovação (SNI), visto que possibilitam a geração de processos inovativos. Assim, objetiva-se neste trabalho avaliar os esforços de capacitação tecnológica decorrentes da interação da empresa Petróleo Brasileiro S.A (Petrobras) com a Universidade Federal de Santa Catarina (UFSC). Para tanto, realizou-se um estudo teórico-empírico, descritivo, bibliográfico e estudo de caso, cuja abordagem adotada foi a qualitativa. Foram realizadas entrevistas com os coordenadores de pesquisa dos laboratórios da universidade, além de consulta aos projetos em parcerias e sites institucionais. Evidenciou-se que a parceria da UFSC e Petrobras é marcada por uma trajetória histórica no que concerne ao desenvolvimento tecnológico, e que propiciou às parcerias o reconhecimento em nível internacional por estas tecnologias de fronteira, como as apresentadas neste estudo, a rocha digital e a avaliação do carregamento em dutos a partir das tensões residuais.
\end{abstract}

Palavras-chave: Interação Universidade-empresa, UFSC, Petrobras, desenvolvimento tecnológico.

JEL: NI

\section{Introdução}

As interações das Universidades com as empresas são características do paradigma tecno-produtivo mundial e possibilitam a realização de projetos e atividades conjuntas direcionadas à promoção da inovação, na medida em que se estabelece a aproximação do conhecimento a demandas do setor produtivo. Conforme Suzigan, Albuquerque e Cario

\footnotetext{
* Às intituições envolvidas.

†Doutora em Administração pela Universidade Federal de Santa Catarina e responsável pela área de desenvolvimento de parcerias e transferência de tecnologia da Secretaria de Inovação da Universidade Federal de Santa Catarina. E-mail: paola.azevedo@ufsc.br

${ }_{\ddagger}$ Professor do Departamento de Economia e Relações Internacionais e dos Programas de Pós-Graduação em Economia e Administração da Universidade Federal de Santa Catarina. E-mail: fecario@yahoo.com.br
} 
(SUZIGAN; ALBUQUERQUE; Cario. S. A. F., 2011) na interação universidade-empresa (U-E) as universidades geram o conhecimento científico, e as empresas, ao agregarem conhecimento tecnológico, geram novas questões para a elaboração científica. Neste processo, Guimarães e Plonski (GUIMARÃES; PLONSKI, 2004) reforçam a necessidade de se constituir um fluxo de conhecimento eficiente entre a universidade e a empresa, a fim de garantir uma transferência efetiva da tecnologia.

Em países situados na América Latina há necessidade do desenvolvimento da interação entre ciência e tecnologia para o processo de catching-up (BERNARDES; ALBUQUERQUE, 2003). Assim, de acordo com Meyer-Kramer e Schmoch (MEYERKRAHMER; SCHMOCH, 1998), a compreensão sobre o processo de interação U-E e o contexto no qual está inserida não deve ocorrer de forma dissociada do desenvolvimento e consolidação do Sistema Nacional de Inovação (SNI). A intensidade das interações pode estar atrelada à capacidade estrutural de absorção das empresas, universidades e do SNI.

Nesta perspectiva, a Petrobras, uma transacional pública que atua de maneira integrada e especializada na indústria de óleo, gás natural e energia, está presente em segmentos de exploração e produção, refino, comercialização, transporte, petroquímica, gás natural, energia elétrica, gás-química e biocombustíveis e distribuição de derivados. Firmou convênio com a UFSC, por mais de duas décadas, no intuito de realizar parcerias com laboratórios de áreas diversas, em especial com as engenharias, para o desenvolvimento tecnológico.

Atualmente esta parceria se consolida por meio de relacionamento com vinte e sete laboratórios da UFSC, dos quais seis deles relacionam-se com a empresa há mais de vinte anos, como o Laboratório de Simulação Numérica em Mecânica dos Fluídos e Transferência de Calor (SINMEC, ), o Laboratório de Meios Porosos e Propriedades Termofísicas (LMPT, ), o Laboratório de Metrologia e Automação (LABMETRO, ), o Laboratório de Tubos de Calor (LABTUCAL, 2017), o Laboratório de Remediação de Águas Subterrâneas (REMAS, 2017), o Laboratório de Pesquisa em Refrigeração e Termofísica. O constante envolvimento e investimento da Petrobras em P\&D tanto junto ao seu próprio setor produtivo, como na interação com universidades e institutos de pesquisa, levou a empresa a desenvolver tecnologia de ponta e se consolidar na liderança tecnológica do setor de petróleo e gás em nível nacional e internacional.

Frente ao exposto, este trabalho tem como objetivo avaliar os esforços de capacitação tecnológica decorrentes da interação da Petrobras com a UFSC. Para tanto, encontra-se dividido em seis seções, sendo que nesta $1^{\text {a }}$. seção apresenta-se a contextualização do problema e o objetivo principal; na $2^{\mathrm{a}}$. seção são destacados alguns aspectos relativos ao aporte teórico; na $3^{\mathrm{a}}$. seção descrevem-se aspectos metodológicos; na $4^{\mathrm{a}}$. seção são apresentados os elementos históricos e recentes de constituição da empresa e de envolvimento no desenvolvimento tecnológico; na $5^{\mathrm{a}}$. seção apresentam-se de maneira sucinta as características quanto à formação dos laboratórios, as principais pesquisas realizadas em parcerias com a empresa e o desenvolvimento de duas tecnologias de ponta decorrentes 
de mais de 20 anos de parceria da UFSC e Petrobras; e, por fim, na $6^{\text {a }}$. seção apresenta-se a conclusão.

\section{O Sistema Nacional de Inovação e as interações universidade-empresa}

O sistema capitalista constitui um modo de produção que se caracteriza por constante mudança e em permanente evolução. Para tanto, as inovações, seja incremental ou radical, constituem elemento central dos processos transformador e evolutivo. Dentre as inovações radicais se encontram as revoluções tecno-produtivas, que vieram firmar paradigmas do processo de acumulação de riqueza. Tais revoluções, no passado, ocorreram no vapor, ferrovia, aço, eletricidade, petróleo e automóvel. E, outras continuam ocorrendo nos dias atuais, como as relacionadas à informática, telecomunicação e microprocessador. Em cada revolução tecno-produtiva, elegem-se elementos-chaves que se traduzem na redução dos custos relativos, aumento da oferta do produto, penetração setorial ampla, novo padrão tecno-produtivo, rejuvenescimento do antigo padrão, novos modos de fazer as coisas, melhores práticas, novos princípios organizacionais, entre outros marcos referenciais (PEREZ, 2004).

Por sua vez, o processo inovativo possui requerimentos básicos para que venha ocorrer. Trata-se de um processo social, interativo e sistêmico, e cada vez mais institucionalizado. Possui propriedades relacionadas aos procedimentos de busca, rotina e seleção; e, de heurística expressa em métodos e regras que se traduzem em descobertas e de resolução de problemas. Para tanto, exigem-se esforços voltados à capacitação tecnológica de empresa, considerada locus da inovação, e de outras esferas institucionais em apoio ao desenvolvimento inovativo. Requer, para tanto, a constituição de um sistema de inovação.

Neste contexto, vários autores definem sistema de inovação como sendo a conformação de uma estrutura institucional dotada de funções e realizando interações voltadas ao desenvolvimento do processo inovativo em determinado espaço geográfico. Para Freeman (FREEMAN, 1995) um sistema de inovação como sendo "[...] uma rede de instituições nos setores público e privado cujas atividades e interações iniciam, importam, modificam e difundem novas tecnologias". Enquanto, para Lundvall, (LUNDVALL, 1992, p. 02) um sistema de inovação refere-se "[...] aos elementos e as relações que interagem na produção, difusão e uso de novos e economicamente úteis conhecimentos [...] localizados tanto dentro, quanto apenas enraizados nas fronteiras de um estado-nação".

No contexto de um sistema de inovação, existem várias abrangências. Há tratamentos que dão ênfase no espaço territorial e outros que enfocam o setor de atividade econômica. No âmbito territorial, este pode assumir a denominação de sistema local de inovação (SLI) abrangendo determinado espaço territorial específico; sistema regional de inovação (SRI) estendendo a estrutura institucional e de funcionamento para um espaço que incorpora, não só um local, mas determinada região territorial que possui características semelhantes; e sistema nacional de inovação (SNI), cuja conformação estrutural abrange a fronteira 
de um estado-nação. Assim como, pode assumir a conformação de determinado setor da atividade econômica, no qual as instituições criam condições para potencializar o processo inovativo, expresso através da denominação de sistema setorial de inovação (SSI) (KRETZER, 2009).

Para o funcionamento de um sistema de inovação devem ser considerados vários fatores, dentre os quais a existência de uma estrutura de ciência e tecnologia (C\&T), peso dedicado da ciência básica no conhecimento, gastos em pesquisa e desenvolvimento (P\&D), especificidades das firmas inovadoras, relações das firmas com os institutos de pesquisa, papel do governo na articulação das instituições, papel das pequenas firmas dinâmicas, diferentes arranjos do sistema financeiro e nível de formação dos trabalhadores (EDQUIST, 1997, 2001). Estes requerimentos devem estar presentes e em funcionamento pleno, pois os resultados podem ser parcos, se o sistema de C\&T não se transforma em agente voltado para um SNI. Assim como, se as empresas são dotadas de posturas limitadas em gastos em P\&D e baixa interação com laboratórios de universidades e de institutos de pesquisa. Da mesma forma, se o governo for passivo em promover articulações com os integrantes de um sistema de inovação.

O foco do sistema de inovação é desenvolver, difundir e utilizar a inovação, por isso, as atividades do sistema são fatores que influenciam a busca pelo processo de inovação. Dentre as atividades mais importantes deste sistema, destaca-se a provisão de $\mathrm{P} \& \mathrm{D}$, desenvolvimento de novos campos de inovação, criação e mudança de instituições, networking através de mercados e outros mecanismos, desenvolvimento de competências, formação de novos mercados de produto, articulação de requisitos de qualidade que emanam do lado da demanda em relação a novos produtos, atividades incubadoras, financiamento de inovação e provisão de serviços de consultoria. É no âmbito das interações entre instituições, organizações e indivíduos que o processo de aprendizado possibilita a realização das inovações. Portanto, a inovação é decorrente de aprendizados sistematizados, no qual a interação é essencial (EDQUIST, 2004).

Nesta linha, Lundvall (LUNDVALL, 2010) aponta que o SNI é um sistema social dinâmico, cuja atividade central está ligada ao aprendizado entre as pessoas. As principais características neste processo são a cumulatividade e círculos virtuosos e viciosos, bem como a reprodução do conhecimento por parte dos indivíduos ou agentes coletivos. Nos círculos virtuosos provenientes da articulação dos atores do SNI ganham destaque as instituições e os mecanismos de interação.

O SNI envolve diferentes participantes, tais como: empresas e suas redes de cooperação e interação; universidades com estruturas voltadas para o ensino, pesquisa e extensão, os institutos de pesquisa em prestação de serviços tecnológicos e em processos inovativos; sistema financeiro com capacidade de apoiar o investimento inovativo; leis reguladoras e incentivadoras; mecanismos mercantis e não-mercantis de seleção; governos em suas diferentes áreas de atuação; mecanismos e instituições de coordenação, entre outras, especificadas na Figura 1, elaborada pela OCDE (1999). Neste contexto, os componentes 
do SNI articulam-se e dão início a processos que eles intitulam de "ciclos virtuosos", nos quais ganham destaque as instituições e os mecanismos de cooperação (BERNARDES; ALBUQUERQUE, 2003; RAPINI, 2008; FERNANDES et al., 2010).

Figura 1 - Participantes de um sistema nacional de inovação

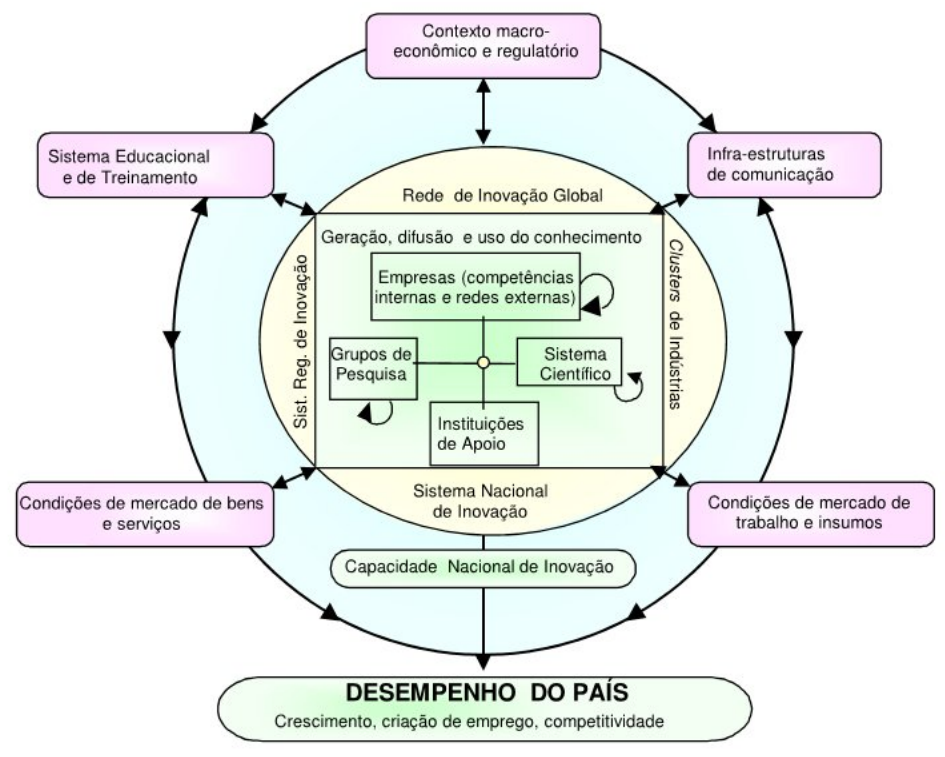

Fonte: OCDE (1999) traduzido por Kern (2009)

O desempenho deste sistema está vinculado a um processo evolucionário, cuja trajetória inclui aspectos concernentes à tecnologia, ao conhecimento, aos atores (empresas, laboratórios, governos, universidades, evolvendo principalmente os arranjos institucionais) (MALERBA, 2007). Portanto, os principais elementos dos SNIs são as instituições, bem como as ligações existentes entre elas, como os próprios fluxos de pessoas e de conhecimento entre universidades, empresas e governo (NIOSI; Niosi; Jorge, 2002).

Suzigan e Furtado (2006) afirmam que o desenvolvimento econômico e social decorre não somente da acumulação de capital físico e humano, mas, principalmente, do aprendizado de novas tecnologias, bem como a forma de compreendê-la a ponto de dominálas. Este desenvolvimento é marcado pela evolução tecnológica e envolve, segundo Dosi $(1988,2006)$, uma expertise específica, resultado da junção da experiência adquirida por meio de esforços e soluções tecnológicas do passado com o conhecimento do estadoda-arte. O conhecimento, por sua vez, persegue um caminho de path dependence, conhecimento acumulado ao longo do tempo, que conforme Lastres e Cassiolato (2005), é entendido como um processo de aprendizado não-linear, cumulativo, localizado e institucionalmente conformado.

Nesse contexto, o meio acadêmico - as universidades - e o meio empresarial - as empresas - são atores estratégicos e fundamentais no processo inovativo, pois traduzem a 
interação entre C\&T e possibilitam o avanço da inovação e desenvolvimento científico do país. As universidades desenvolvem o conhecimento essencial para a inovação, e trazem respostas científicas às demandas oriundas das empresas. Desta forma, torna-se salutar estabelecer canais de comunicação direta com a empresa, como fontes primordiais no processo inovativo (MACULAN, 2005; RAPINI, 2008).

Alvim (1998) e Cunha (1999) apontam que a interação U-E pode assumir diferentes formas, dentre as quais: apoio técnico, assistência, consultoria e prestação de serviço pela universidade; serviços técnicos repetitivos, tais como análise de laboratórios, ensaios, entre outros e serviços especializados, específicos e encomendados; oferta de informação especializada; programas de capacitação de recursos humanos, como cursos e eventos de atualização; programas de formação de recursos humanos; bolsa para estudantes que pesquisam temas de interesse das empresas; intercâmbio de pessoal; divulgação de oportunidades de trabalho para alunos; organização de seminários e reuniões conjuntas; contatos pessoais; intercâmbio de publicações; pesquisa cooperativa; redes cooperativas; transferência de tecnologia e parques tecnológicos. Outra contribuição analítica referência é elaborada por D'Este e Patel (2007), cujo teor aponta a existência de cinco tipos de interação entre U-E, as reuniões e conferências, consultoria e contrato de pesquisa, criação de instalação física, a formação e a pesquisa associada.

Por seu turno, muito se questiona a maneira pela qual as relações U-E são firmadas. Neste sentido, salienta-se a contribuição de Bonaccorsi e Piccaluga (1994), cujo texto aponta que as relações podem assumir caráter pessoal, seja informal (consultorias individuais e reuniões informais) ou de acordos formalizados (contratos firmados para troca de pessoal, intercâmbio de alunos e colaboradores); existência de uma terceira parte, via instituição de intermediação (associações industriais e consultoria institucional); ocorrência de acordos e convênios formais com objetivo definido (pesquisas contratadas, desenvolvimento de protótipos e testes); firmamento de acordos e convênios formais sem objetivo definido (patrocinadores de pesquisa e desenvolvimento industrial nos departamentos universitários); e, criação de estruturas próprias para a interação (centros de incubação de inovação, parques tecnológicos, institutos e laboratórios).

Existem, por sua vez, diferentes motivações que levam a ocorrência de interações UE. Segundo Segatto e Sbragia (1998), no âmbito da universidade estão postos os seguintes motivos incentivadores: recursos financeiros adicionais, recursos materiais adicionais, realização da função social, prestígio para o pesquisador, divulgação da imagem da universidade, aumento do conhecimento sobre os problemas existentes e incorporação de novas informações nos processos de ensino e pesquisa. Enquanto, para as empresas, as motivações ocorrem em função de: acesso a recursos humanos especializados, redução de custos e riscos, acesso a novos conhecimentos, identificação de alunos para recrutamento futuro e resolução de problemas técnicos. Barreiras à interação também existem, dentre as quais citam-se: grau de incerteza dos projetos, localização geográfica, burocracia da universidade, propriedade de patentes e resultados, duração do projeto, apoio governamental,

Econômica-Niterói, v. 20, n. 2, p. 59-84. Dezembro, 2018 
diferença de nível de conhecimento, dentre outros.

\section{Metodologia}

Trata-se de uma pesquisa de natureza qualitativa, estudo de caso, descritiva, documental e bibliográfica. Desta forma, buscou-se compreender os esforços de inovação tecnológica provenientes da interação UFSC e Petrobras. Para tanto, inicialmente foi realizado o mapeamento de todos os projetos realizados pela Universidade e empresa que constavam nas fundações de intermediação FEESC e FAPEU, no período de dezembro de 2014 a dezembro de 2015. Após este levantamento, foi realizada a conferência da ocorrência dos projetos com o Departamento de Inovação Tecnológica (DIT) da UFSC, o qual atualmente denomina-se Secretaria de Inovação (SINOVA).

Após o mapeamento de projetos, verificou-se que vinte e sete laboratórios de pesquisa interagem com a Petrobras, totalizando cinquenta e nove projetos neste período. A partir destes dados, foram selecionados os laboratórios que interagem com a empresa há mais de vinte anos, e que juntos respondem por mais de $50 \%$ dos projetos realizados em parceria com a Petrobras, sendo eles o Laboratório de Simulação Numérica em Mecânica dos Fluídos e Transferência de Calor (SINMEC), o Laboratório de Meios Porosos e Propriedades Termofísicas (LMPT), o Laboratório de Metrologia e Automação (LABMETRO), o Laboratório de Tubos de Calor (LABTUCAL) e o Laboratório de Pesquisa em Refrigeração e Termofísica (POLO, 2017), os quais são vinculados ao Departamento de Engenharia mecânica e o Laboratório de Remediação de Águas Subterrâneas (REMAS).

A partir dos laboratórios selecionados, optou-se pela caracterização do início das parcerias, dos principais projetos em parcerias realizados pelos laboratórios, e posteriormente foram selecionadas duas tecnologias, desenvolvidas em dois destes laboratórios, as quais elucidam o resultado evolutivo da parceria em longo prazo, para demonstrar de que maneira o aprendizado acumulado permitiu o desenvolvimento tecnológico decorrente da interação UFSC e Petrobras. A fim de compreender como ocorreu esta evolução numa perspectiva histórica, os coordenadores dos laboratórios nos quais foram desenvolvidas as tecnologias em estudo foram entrevistados por meio de uma entrevista semi-estruturada.

A análise dos dados ocorreu de acordo com o modelo de Triviños (TRIVIÑOS, 2006), o qual propõe três etapas: pré- análise, descrição analítica e interpretação referencial. Assim, inicialmente agruparam-se os materiais relacionados, o resultado das entrevistas (transcrições) e os dados secundários, que se caracterizaram pelos dados dos projetos pesquisados nos sites da FAPEU e FEESC, bem como informações coletadas nos sites institucionais da Petrobras e dos laboratórios da UFSC analisados (SINMEC, LMPT, LABMETRO, LABTUCAL, POLO e REMAS). Posteriormente, os resultados foram descritos, analisados e interpretados. 


\section{A Petrobras e os investimentos em pesquisa e desenvolvimento}

A Petrobrás, criada em 03 de outubro de 1953, é uma transnacional brasileira pública, que atua como uma empresa integrada de energia nos setores de exploração e produção, refino, comercialização, transporte, petroquímica, distribuição de derivados, gás natural, energia elétrica, gás-química e biocombustíveis. Atualmente está presente em dezoito países e compõem-se de 86.111 trabalhadores com operações em 21 Estados e no Distrito Federal. Estas não aparecem apenas nos seguintes estados: Acre, Piauí, Roraima, Rondônia e Tocantins.

A empresa fundou em 1955 o Centro de Aperfeiçoamento e Pesquisas de Petróleo (CENAP), que visava à capacitação técnica e a substituição de profissionais estrangeiros por brasileiros. $\mathrm{O}$ aumento de atividades vinculadas à $\mathrm{P} \& \mathrm{D}$ resultaram na criação do Centro de Pesquisas e Desenvolvimento Leopoldo Américo Miguez de Mello (CENPES) em 1963, que inicialmente adaptava tecnologias importadas para as condições ambientais, geológicas, de mercado e das matérias-primas nacionais e atualmente é um dos complexos de pesquisa aplicada mais importantes do mundo.

O CENPES é composto por uma gerência executiva e oito gerências gerais, das quais cinco ligadas à P\&D: P\&D em Geociências, P\&D em Geoengenharia e Engenharia de Poço, P\&D em Engenharia de Produção, P\&D em Abastecimento e Biocombustíveis e P\&D em Gás, Energia e Desenvolvimento Sustentável. A maior parte dos investimentos está direcionada para a principal atividade da empresa, exploração e produção. Em média, $85 \%$ do valor são direcionados ao desenvolvimento da produção, $12 \%$ para exploração, e $3 \%$ para suporte operacional, com ênfase no Pré-Sal.

O relacionamento estratégico entre o CENPES e as Universidades ocorre por meio dos núcleos regionais de competência, das redes temáticas existentes na empresa de interesse do segmento petróleo, gás e energia e do relacionamento direto na gestão de projetos de P\&D. Atualmente a empresa mantém relações, por meio do CENPES, com cerca de 100 universidades e centros de pesquisas no Brasil e 35 no exterior, através das 49 redes temáticas, de 1.145 termos de cooperação assinados com instituições brasileiras e 173 termos de cooperação realizados com instituições estrangeiras. Estes investimentos em Universidades e instituições garantem a sustentabilidade do processo de desenvolvimento conjunto de projetos de pesquisa que culminam em novas tecnologias (PETROBRAS, 2017).

Com o passar dos anos e parcerias firmadas entre o CENPES, universidades e instituições de pesquisa, a Petrobrás depositou 1.879 patentes em órgãos de patenteamento, das quais 944 patentes no Brasil e 935 em outros países, de 1980 a 2010, o que consolidou esta empresa como maior depositante de patentes no Brasil, dentre elas, a UFSC. Dos países no qual há maior depósito de patentes por parte da empresa, destaca-se os Estados Unidos, com 244 patentes depositadas entre 1980-2010. Alcançou a média de 17 patentes por ano no período de 2006 a 2010. O número de patentes depositadas no Brasil decor-

Econômica-Niterói, v. 20, n. 2, p. 59-84. Dezembro, 2018 
rentes de atividade inovadora é crescente, pois a média anual de patentes de 1980 a 1990 foi de 26, a qual passou para 65, de 1991 a 2000 e atingiu patamares ainda maiores de 2001 a 2010, alcançando a média de 94 patentes depositadas por ano.

A promulgação da Resolução Agência Nacional de Petróleo (ANP) no. 33, em 2005, determinou que os concessionários deveriam realizar despesas qualificadas em P\&D em torno de $1 \%$ da receita bruta, sendo que deste valor, metade destinado aos Institutos de Ciências e Tecnologias (ICTs) nacionais, impulsionando, ainda mais, não só desenvolvimento interno, mas também os investimentos da empresa em $P \& D$ juntos às universidades e institutos de pesquisa. $\mathrm{O}$ valor dos investimentos da Petrobrás em $\mathrm{P} \& \mathrm{D}$ sinalizam como uma das maiores empresas investidoras em $P \& D$ na área de energia no mundo, conforme o Gráfico apresentado pela figura 2. Conforme relatório publicado pela empresa em 2013 as despesas da Petrobrás em P\&D no ano de 2012 totalizaram US\$ 1.143 milhões, 0,8\% da receita liquida da empresa. Observa-se que a empresa investiu mais em 2013 em termos relativos do que as demais grandes empresas de energia em nível mundial.

Figura 2 - Despesas em P\&D de grandes empresas de energia no mundo, 2012

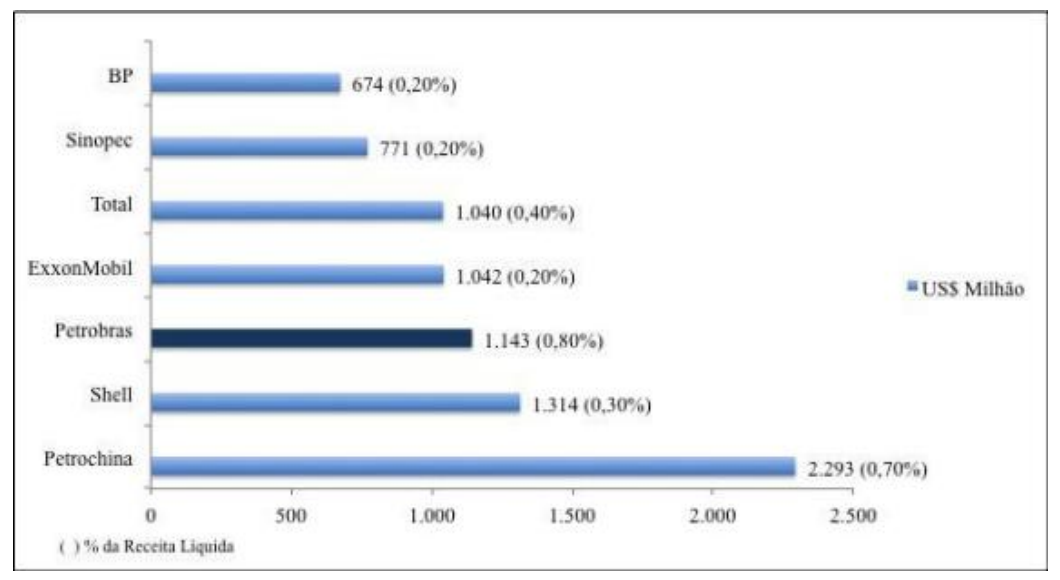

Fonte: Relatório de Diretoria da PETROBRAS (2017)

Em 2014 foram realizados investimentos em P\&D da ordem aproximada de US\$ 1,1 bilhão. Contudo, esse não fora o maior valor registrado na série histórica de 2001 a 2014. O maior valor investido nesta área foi no ano de 2011, próximo de US\$1,5 bilhão. Os investimentos nos anos de 2015 e 2016 foram respectivamente de $\mathrm{R} \$ 2$ bilhões e R $\$ 1,8$ bilhões. O Gráfico apresentado pela figura 3 mostra a evolução crescente das inversões em processos de busca inovativa, ainda que tenha ocorrido redução em 2009, cuja razão deve ser encontrada no momento em que a economia mundial deparou com forte crise econômica. Esse ano foi cercado de muitas incertezas em relação ao futuro da economia, refletindo negativamente no valor dos investimentos da empresa em P\&D.

Oliveira e Figueiredo (2013) analisaram as características dos investimentos em P\&D 
Figura 3 - Investimento em P\&D da Petrobrás, Brasil, de 2001 a 2014

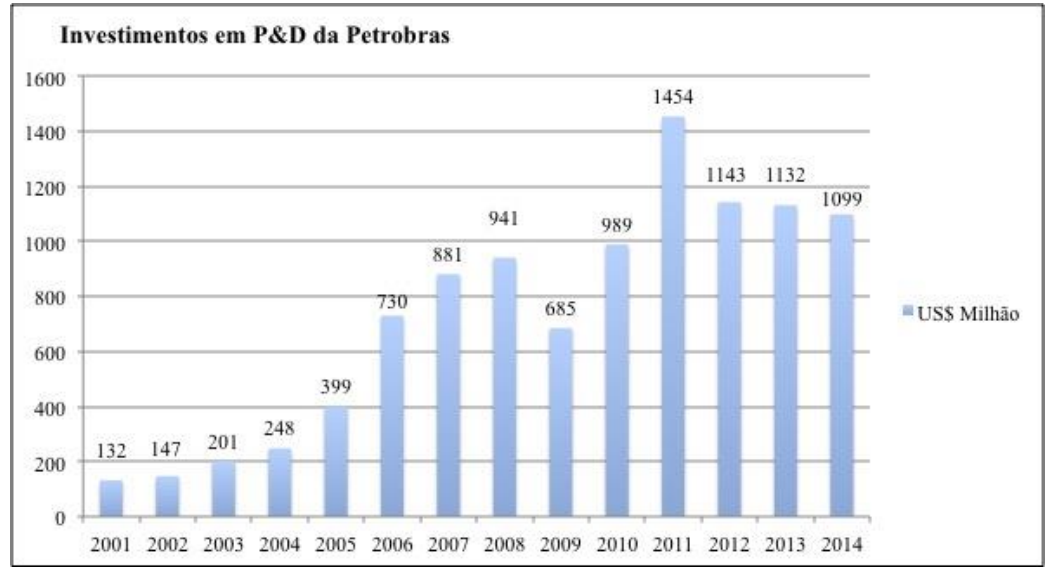

Fonte: Elaborado pelos autores a partir do Relatorio PETROBRAS (2017)

da Petrobrás os quais envolveram os contratos e convênios realizados com 196 ICTs, empresas nacionais e estrangeiras. O resultado deste estudo apontou a evolução dos aportes financeiros investidos pela empresa em P\&D no período de 1992 - 2009, por região, estados e instituições de pesquisas nacionais. Os investimentos e interações foram propiciados pelo CENPES. De 1992 a 2009, a empresa investiu R \$ 3.329 bilhões em uma extensa rede de ICTs no Brasil. Neste período a região do Brasil que obteve maior volume de recursos investidos foi a Sudeste, com 74,9\% do valor total, seguidos do Nordeste 12,4\%, Sul com 9\%, Norte 2,6\% e Centro-oeste com 1,1\%. As cinco instituições que mais receberam recursos foram UFRJ, PUC-RIO, USP, UNICAMP e UFRN. A UFSC ocupou a sétima posição, com $2,4 \%$ dos recursos. Dos recursos destinados às ICTs, $80 \%$ dos valores contratados foram direcionados para 33 instituições, conforme o gráfico apresentado pela figura 4. Do total investido, 53,1\% foram para ICTs federais ou vinculadas a instituições de ensino federais, $12,5 \%$ para ICTs estaduais ou ligadas a instituições de ensino estaduais e $14,4 \%$ para ICTs privadas.

Os avanços tecnológicos alcançados pela Petrobras são resultantes de anos de investimento em P\&D, como ilustrado anteriormente, vinculados às operações internas da empresa, cujo aprendizado é decorrente dos mecanismos de aprendizado - learning by search (laboratórios) e learning by doing (outros espaços) e em relações de com universidades e institutos de pesquisa, com foco no desenvolvimento tecnológico e inovativo, manifestado através do learning by interacting (interações e parcerias externas). Estes avanços e conquistas em nível mundial tornaram a empresa e as Universidades parceiras de referência no desenvolvimento de tecnologia no setor de petróleo e gás. Dentre estes atores parceiros estratégicos para empresa, destaca-se a Universidade Federal de Santa Catarina, a qual interage com a Petrobras há aproximadamente trinta anos.

Econômica-Niterói, v. 20, n. 2, p. 59-84. Dezembro, 2018 
Figura 4 - Distribuição das unidades dos contratos em 80\% valores da Petrobrás, Brasil, 2013

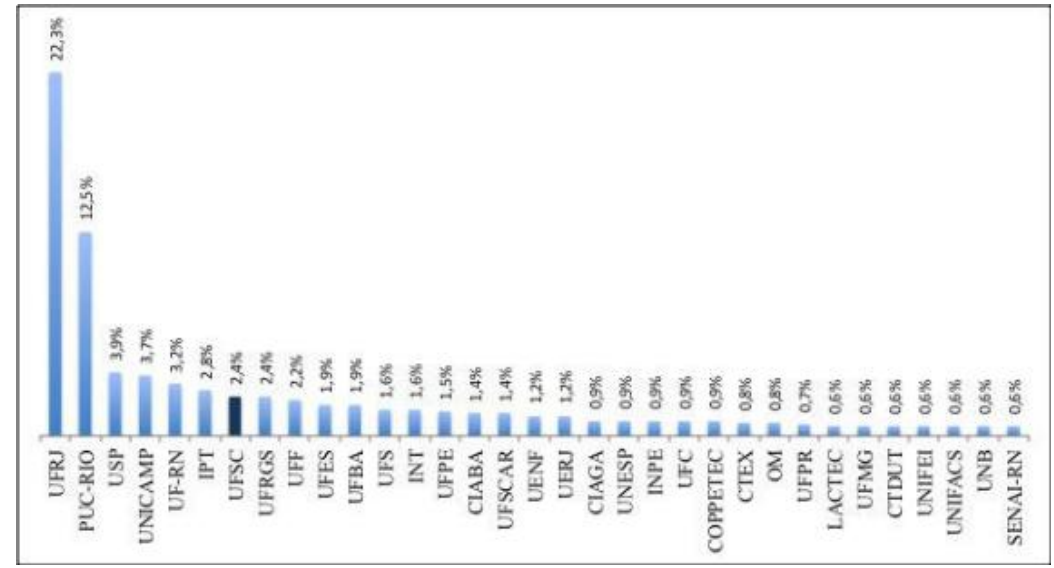

Fonte: Oliveira e Figueiredo (2013).

\section{Laboratórios de pesquisa da UFSC: projetos de P\&D e avanços tec- nológicos}

As interações entre a Petrobras e os laboratórios de pesquisa da UFSC tem uma trajetória histórica, a qual acompanha o desenvolvimento e avanço tecnológico da empresa. $\mathrm{O}$ início das parcerias iniciou de diferentes formas, porém, uma característica marcante de todas elas é a especialidade dos pesquisadores e peculiaridade da área de estudo, o que os fez potencias parceiros da empresa, por meio dos laboratórios. As parcerias iniciaram tanto por contato iniciado pela empresa, como pelos próprios pesquisadores da Universidade. Estas parcerias começaram em congressos, por meio de ex-alunos que foram trabalhar na empresa, pelo fato de o grupo de pesquisa ser reconhecido em área de interesse da empresa e por meio das redes temáticas, as quais foram estabelecidas pela Petrobras em 2006. Outro ponto marcante nesta interação é a ausência de editais para realização de projetos.

Atualmente esta parceria se consolida por meio de interação com vinte e sete laboratórios da UFSC, dos quais seis deles relacionam-se com a empresa há mais de vinte anos, como o Laboratório de Simulação Numérica em Mecânica dos Fluídos e Transferência de Calor (SINMEC), o Laboratório de Meios Porosos e Propriedades Termofísicas (LMPT), o Laboratório de Metrologia e Automação (LAB/METRO), o Laboratório de Tubos de Calor (LABTUCAL) e o Laboratório de Pesquisa em Refrigeração e Termofísica (POLO), os quais são vinculados ao Departamento de Engenharia Mecânica e o Laboratório de Remediação de Águas Subterrâneas (REMAS), ligado ao Centro Tecnológico (CTC). 


\subsection{Laboratório de Simulação Numérica em Mecânica dos Fluídos e Transferência de Calor - SINMEC}

O SINMEC foi criado em 1981 e seu foco é o desenvolvimento de metodologias numéricas, por meio, do método dos volumes finitos para problemas que incluam escoamento de fluidos e transferência de calor. Além do desenvolvimento de algoritmos, o laboratório aplica estas tecnologias para problemas de engenharia, principalmente para escoamentos multifásicos e escoamentos em reservatórios de petróleo.

Este laboratório desenvolve projetos de implantação de infraestrutura física da rede de fluidodinâmica computacional em processos de refino. Além disso, o SINMEC atua em outros dois projetos vinculados à Petrobras, o simulador bifásico tridimensional em malhas híbridas e avanços para o desenvolvimento de um plug-in usando malhas de transição, e o estudo numérico e experimental da termofluidodinâmica de bombas multifásicas de duplo parafuso.

\subsection{Laboratório de Tubos de Calor - LABTUCAL}

O LABTUCAL realiza pesquisas nas áreas de energia solar e transferência de calor aplicada, incluindo o desenvolvimento de tecnologia de tubos de calor, cujas pesquisas ocorrem desde o princípio dos anos 1990. As pesquisas atuais dividem-se em dois enfoques principais, no primeiro são estudados os fenômenos físicos envolvidos na operação de tubos de calor e/ou termossifões, os quais são analisados teórica e experimentalmente em diferentes níveis de temperatura. No segundo são desenvolvidos equipamentos que empregam a tecnologia de tubos de calor e termossifões para a indústria do Petróleo.

Em virtude da interação do laboratório com a Petrobras, o LABTUCAL atua em projetos voltados para o desenvolvimento de tecnologia de destilação de películas, de trocadores de calor compactos e no desenvolvimento de tecnologias para trocadores de calor assistidos por termossifões - TTTER. O último visa capacitar a Universidade para realização de pesquisas, estudos e testes. Além destes projetos, cabe ressaltar o desenvolvimento em parceria de permutadores de calor compactos soldados por difusão, o qual encontrase na segunda fase do projeto, o que significa que há uma trajetória de desenvolvimento desta tecnologia e que esta é resultado de aprendizado acumulado.

\subsection{Laboratório de Pesquisa em Refrigeração e Termofísica - POLO}

O POLO realiza pesquisas há mais de trinta anos e na atualidade é referência mundial em pesquisa, desenvolvimento e inovação em refrigeração e termofísica. As pesquisas estão voltadas para o aprimoramento dos conceitos e aperfeiçoamento do desempenho de componentes e sistemas de refrigeração, tanto domésticos, comerciais, automotivos ou de aeronaves.

Econômica-Niterói, v. 20, n. 2, p. 59-84. Dezembro, 2018 
Além de a Petrobras participar em parceria na implantação e melhoria de infraestrutura laboratorial na UFSC visando a capacitação da Universidade para pesquisa, estudos e testes futuros, o POLO interage com a empresa através dos projetos de caracterização teórica e experimental das propriedades termofísicas de misturas de óleo e CO2 e altas pressões e altas temperaturas, e de fenômenos térmicos em poços de petróleo e gás, cujo objetivo é compreender estes fenômenos com intuito de estabelecer diretrizes para seleção de materiais e configuração de sistemas de isolamento térmico em poços expostos a condições de operações extremas.

\subsection{Laboratório de Remediação de Águas Subterrâneas - REMAS}

O REMAS está relacionado ao Centro Tecnológico e é composto por uma equipe que realiza pesquisa e atividades interdisciplinares, com intuito de alcançar soluções integradas para problemas complexos correlacionados à indústria do petróleo e seus impactos ambientais. Assim, as pesquisa estão direcionadas para problemática da contaminação de solos e águas subterrâneas por combustíveis de petróleo e biocombustíveis (tecnologias de biorremediação e modelagem matemática).

Além de toda estrutura criada na Fazenda Ressacada criada por meio da interação do REMAS com a Petrobras, o laboratório trabalha em parceria com a empresa para adequar, aperfeiçoar e customizar o modelo matemático SCBR para previsão de cenários acidentais e apoio ao gerenciamento ambiental de áreas contaminadas no setor de petróleo e gás, e no desenvolvimento do projeto de biotecnologias ambientais para biocombustíveis, com intuito de capacitar a universidade para a realização de pesquisas, estudos e testes, e /testes/estudos.

\subsection{Laboratório de Meios Porosos e Propriedades Termofísicas - LMPT}

O LMPT desenvolve desde 1981 pesquisas fundamentais e aplicadas em diferentes áreas. Atualmente as pesquisas estão vinculadas à área de materiais porosos, interação entre fluidos e entre fluido e superfícies sólidas e instrumentos para medição de variáveis térmicas. Dentre estas, destaca-se a área de materiais porosos, cujo objetivo é a caracterização microestrutural e a modelagem da correlação entre a microestrutura e as propriedades físicas do material, as quais são essenciais para áreas como petróleo e gás, hidrologia de bacias, construção civil, dentre outras.

Além da implantação da infraestrutura do laboratório de meios porosos e propriedades termofísica por parte da empresa, O LPMT atua em parceria com a Petrobras para: compreender os Sistemas Porosos multiescalares, por meio da caracterização petrofísica computacional e quantificação experimental da distribuição de fluídos com tomografia de Raios-X de alta resolução; desenvolver o Imago 3D, um software de processamento e análise de imagens tridimensionais; simular e realizar o experimento do efeito molhabili- 
dade sobre o deslocamento de água-óleo em micromodelos de sistemas porosos, por meio de abordagens computacional e experimental; desenvolver um método que caracterize o sistema poroso e determine computacionalmente as propriedades petrofísicas de amostras de carbonatos ; e realizar a caracterização petrofísica de rochas de baixa permeabilidade.

\subsection{Laboratório de Metrologia E Automação - LABMETRO}

O LABMETRO desenvolve atividades de interação desde o surgimento do curso de Engenharia mecânica na década de setenta. O laboratório se consolidou ao longo dos anos como referência nacional em metrologia, instrumentação e automação da medição. As pesquisas realizadas pelo laboratório envolvem temas como: instrumentação mecatrônica de medição, inspeção e controle; automação de ensaios; sistemas de medição e inspeção por técnicas ópticas; inteligência artificial aplicada em laboratórios e linhas de produção industrial.

Além da infraestrutura de ponta decorrente da parceria com a Petrobras e da implantacao da infraestrutura fisica do laboratorio de tecnicas avancadas de ensaios, soldagem e inspecao de dutos e implantacao de laboratorios adicionais do INPetro. O laboratório mantém projetos como o SHIC II - Shearografia para inspecao de compositos e faz avaliacao do carregamento em dutos a partir das tensoes residuais. Assim como, realiza desenvolvimento do perfilometro optico a laser para mapeamento de dutos - perola - em fase II.

\section{Avanços tecnológicos a partir da interação UFSC-PETROBRÁS}

As Universidades e a empresas são elementos-chaves no SNI, pois em conjunto e através da interação promovem o avanço tecnológico, na medida em que as universidades desenvolvem o conhecimento necessário para a inovação e fornecem respostas científicas às demandas levantadas pelas empresas. Como já exposto por Maculan (2005), em virtude deste cenário, torna-se essencial estabelecer canais de comunicação direta com a empresa, como fontes essenciais ao processo inovativo.

Como mencionado por Dosi (2006), o conceito de tecnologia engloba também uma expertise específica, resultado da junção da experiência adquirida por meio de esforços e soluções tecnológicas do passado com o conhecimento do estado-da-arte. Neste sentido, são apresentados na sequência os principais aspectos relativos aos avanços tecnológicos (evolução e modificações) propiciados pela interação da UFSC com a Petrobrás ao longo de mais de vinte anos de parceria, representados neste estudo de maneira sucinta por duas tecnologias desenvolvidas em parceria com a Petrobras em dois dos laboratórios, descritos anteriormente. 


\subsection{Laboratório A - Sistemas porosos multiescalares: carbonatos oriundos do Pré- Sal}

Uma das tecnologias selecionadas foi os Sistemas Porosos Multiescalares: caracterização, petrofísica computacional e quantificação experimental da distribuição de fluidos com tomografia de raios $\mathrm{X}$ de alta resolução (PoroFluidoCarb). Trata-se de um projeto correlacionado ao tema rocha digital aplicado em sistemas porosos com múltiplas porosidades (multiescalares), especificamente carbonatos.

Conforme o coordenador do laboratório, os principais objetivos do projeto são o aperfeiçoamento de técnicas e métodos para a caracterização da morfologia e da conectividade de carbonatos, a partir de imagens 3-D obtidas com tomografia computadorizada de raios-X de alta resolução; o desenvolvimento e implementação numérica de modelos matemáticos para a integração de escalas espaciais do sistema poroso, representado em rede de poros e ligações conservando a conectividade entre as escalas; a simulação de propriedades petrofísicas, curvas de pressão capilar e permeabilidade absoluta visando validar as técnicas; e a realização de experimentos para a visualização e quantificação de fases fluídicas em equilíbrio mecânico no sistema poroso (curvas de pressão capilar), com o uso de microtomografia de raios-X.

As tecnologias desenvolvidas no laboratório e que resultaram no projeto supracitado são decorrentes da parceria com a Petrobrás e estão em desenvolvimento há vinte anos, por isso tem uma trajetória tecnológica, segundo o coordenador: "Posso dizer que a tecnologia que a gente está desenvolvendo em parceria é a mesma desde 1996. Ela tem dados saltos extremamente relevantes. É interessante como nestes 20 anos esta tecnologia foi avançando significativamente". O depoimento do coordenador e a sinalização de Edquist (2004) apontam que a inovação decorre do aprendizado individual e organizacional sistematizado e acumulado, na qual a interação U-E é fundamental.

A tecnologia analisada é a rocha digital, comumente compreendida através das imagens do sistema poroso das rochas. Desta forma, são realizados os processamentos de imagens, a caracterização da morfologia e da conectividade do sistema poroso. Há mais de dez anos a imagem existente era de uma lâmina delgada, uma imagem bidimensional. A mudança do 2D para o 3D foi lenta e, durante muito tempo, as pesquisas mais relevantes do laboratório foram voltadas para esta descoberta, como mencionado pelo coordenador: "A gente trabalhou muito tempo, foi uma linha de pesquisa atuante: reconstrução estocástica. Eu só enxergava uma exceção, mas precisava ver a coisa em 3D, então virtualmente eu criava um modelo 3D a partir de informações medidas no 2D. Eram extremamente limitados, funcionavam em alguns casos em outros não".

As transformações nas tecnologias mundiais trouxeram uma mudança de cenário para o projeto do laboratório em parceria com a Petrobras, pois surgiram comercialmente os microtomógrafos e raio $\mathrm{X}$, os quais permitem a obtenção das imagens de 3D diretamente, e, em virtude disso, os softwares que realizavam a verificação das imagens tiveram que 
ser adaptados. Segundo o coordenador: "Esta tecnologia foi excelente, aqui eu tinha um modelo, agora eu tenho uma imagem mais fidedigna da rocha, só que aí o volume de dados é muito maior, os softwares precisavam ser adaptados para isso, aí vem todo um trabalho para adequação".

O pesquisador destaca ainda os atuais desafios da pesquisa. De 1995 até 2004 o trabalho dos pesquisadores estava direcionado para os arenitos (rochas oriundas da Bacia de Campos - RJ). De 2005 até o presente momento, os pesquisadores investigam os carbonatos (provenientes do Pré-Sal). Próximo ao ano de 2005, a tecnologia já utilizando a tomografia de raio $\mathrm{X}$ tornou-se bastante confiável para os arenitos, os quais são grãos de areais que depositam com argila e caracterizam-se por ser uma estrutura mais simples que um carbonato. $\mathrm{O}$ arenito é mecânico basicamente, e pode ser visto tudo numa única imagem. É possível observar os poros com uma única resolução espacial, por isso, era visto como sistema monoescala. Atualmente, o desafio está centrado nos carbonatos.

O carbonato é uma estrutura porosa mais complexa, pois envolve questões mecânicas, químicas e biológicas. Há a necessidade de várias imagens para o carbonato ser observado, normalmente, duas ou três resoluções espaciais, escalas espaciais, por isso o nome de sistemas multiescalares. É possível visualizar tudo em relação ao arenito, já o carbonato traz dificuldades, por isso, é tema da pesquisa atual. Trata-se de um grande desafio para quem estuda rochas relacionadas ao Pré-Sal, sendo, portanto, uma pesquisa de ponta, conforme ratifica o coordenador:

"Com os carbonatos você observa e há coisas grandes, você vê uma escala, aí você dá um zoom e vai ver que tem coisas menores, vai para um terceiro escala, então você tem que juntar tudo isso, e este problema não é resolvido atualmente no mundo. Nós estamos trabalhando nisso, é nossa pesquisa atual, os sistemas porosos multiescalares, é pesquisa de ponta, pois estamos na fronteira tecnológica. Então, é uma tecnologia que vem ao longo dos anos sendo aprimorada, nossos desafios surgem, o principal desafio foi este do carbonato".

Considerando a complexidade das estruturas porosas, a necessidade de sistemas multiescalares e por conta de ser muito recente, eles precisaram iniciar novos modelos, como aponta o coordenador:

\footnotetext{
"Como as estruturas porosas são muito mais complexas, exigem várias imagens, nós tivemos então que começar a fazer novos modelos para dar conta destes problemas das várias escalas espaciais. Os carbonatos representam metade das reservas de hidrocarboneto no mundo, mas aqui no Brasil a geologia do que toca ao pré-sal é algo novo, com muitas questões a serem respondidas, e é isso que estamos estudando".
}

A explanação acerca da pesquisa realizada por este laboratório da UFSC em parceria com a Petrobras há mais de vinte anos, evidencia que se trata de uma pesquisa situada

Econômica-Niterói, v. 20, n. 2, p. 59-84. Dezembro, 2018 
na fronteira tecnológica, a qual, segundo Arend (2009), diz respeito ao nível mais alto alcançado em relação a uma trajetória tecnológica e quando esta é muito poderosa, pode resultar em dificuldade em modificá-la para uma trajetória alternativa, como pode ser observado no caso deste projeto.

\subsection{Laboratório B - Avaliação de carregamentos em dutos a partir das tensões resi- duais}

Outro avanço tecnológico proveniente da interação com a Petrobrás surgiu a partir do projeto relativo à avaliação do carregamento em dutos, a partir das tensões residuais (CARD3). De acordo com o coordenador, o objetivo é o desenvolvimento de equipamentos e procedimentos aplicáveis em campo (na faixa) para avaliar a integridade dos dutos e o nível de risco de acidentes a que estão sujeitos trechos críticos de dutos expostos a severos carregamentos externos, decorrentes de movimentações do solo e encostas. A tecnologia desenvolvida, por meio da pesquisa, é criar um aparelho para ser usado no propósito de medir tensões em dutos.

A primeira versão do aparelho era de bancada, media aproximadamente $2 \mathrm{mtx} 2,5 \mathrm{mt}$. Na sequência foram desenvolvidas as primeiras versões semi-portáteis, as quais evoluíram em outras versões e melhoraram paulatinamente a imagem produzida. Esta trajetória levou a versão com óptica difrativa e atualmente, ao dispositivo portátil robusto, o qual opera em qualquer posição, facilitado por ser de pequeno porte. Inicialmente, este equipamento funcionava somente sobre a mesa, e a partir das evoluções, chegou numa versão portátil com alta qualidade de imagem e bastante disputada no mercado. Em relação ao estágio atual, expressa o coordenador: "Eu te digo com segurança que este é o equipamento mais evoluído do mundo nesta direção, ele tem características que você não encontra em nenhum outro sistema que está no mercado".

O laboratório que desenvolveu este aparelho tem mais de vinte anos de interação com a Petrobrás e outros projetos renovados ao longo dos anos para o desenvolvimento de tecnologia, o que possibilita que o conhecimento seja acumulado, resultando na aprendizagem tecnológica. A afirmação do coordenador referenda este quadro: "Nós fomos aprendendo aos poucos e hoje a gente sabe fazer melhor do que um tempo atrás. Em um projeto de 2 ou 3 anos, você não consegue fazer de forma completa, há avanços e você aprende como fazer melhor algumas coisas, mas se você tiver mais tempo e recurso, você avança de fato no desenvolvimento tecnológico." Tal constatação está em consonância com observações de Lastres e Cassiolato (2005) de que a inovação é compreendida como um processo de aprendizado cumulativo e não-linear, específico do local e institucionalmente conformado.

Este projeto atual é resultado de uma trajetória de mais de vinte anos, como ilustrado na linha do tempo apresentada na Figura 5. Os esforços de capacitação tecnológica para obter o medidor portátil e robusto de tensões residuais iniciaram em 1989, e desde este 
ano até 2016 foram realizados como cumprimento de pequenas metas da pesquisa aproximadamente dez dissertações e cinco teses correlacionadas a estes projetos que ocorreram por meio da parceria com a Petrobras, além dos trabalhos que estão em andamento. Todos os projetos foram realizados com intuito de se obter um aparelho capaz de medir tensões em dutos. No princípio, a versão inicial do aparelho media em torno de $5 \mathrm{~m} 2$, posteriormente diminuiu de tamanho e tornou-se uma versão semi-portátil. Ao longo dos projetos chegou-se a um aparelho portátil, pequeno e houve uma significativa melhoria das imagens promovidas por ele.

Figura 5 - Trajetória temporal da medição de tensões residuais com laser decorrentes dos projetos de interação UFSC e PETROBRAS

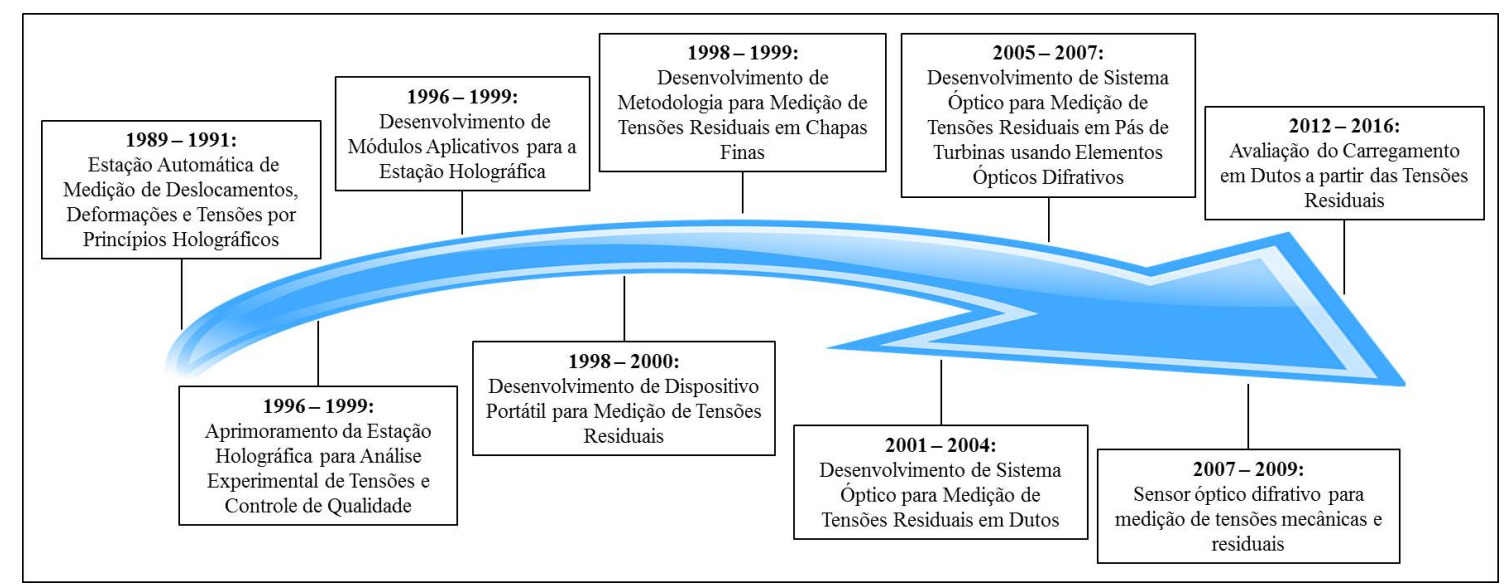

Fonte: Azevedo (2016) a partir de Junior (2016)

Tal ilustração aponta a existência de uma trajetória tecnológica, que de acordo com Dosi (2006), é um aglomerado de direções tecnológicas possíveis, do desenvolvimento de um aparelho usado pela Petrobrás, e continuamente aprimorado no laboratório da UFSC. A última versão está em desenvolvimento e é resultado de uma longa trajetória percorrida, como pode ser observada na expressão do coordenador:

"Nós fomos desenvolvendo, aperfeiçoando e melhorando os projetos, e
hoje o resultado deste último projeto está muito bom, e isso faz parte
do processo de evolução tecnológica, tem que ter esta trajetória, pois
qualquer coisa séria que você faça precisa de trabalhos progressivos,
algo bom. Uma inovação precisa de pelo menos 10 anos, menos que
isso, você não consegue evoluir muito, ou o suficiente para se destacar".

A evolução do aparelho desenvolvido nestes anos para a medição de tensões residuais, resultado da interação UFSC-Petrobrás para desenvolvimento inovativo, pode ser observado na sequência de imagens apresentadas nas figuras 6, 7, 8, 9, 10 e 11. Esta sequência

Econômica-Niterói, v. 20, n. 2, p. 59-84. Dezembro, 2018 
de projetos e imagens elucida a trajetória tecnológica do desenvolvimento de um aparelho que é utilizado pela Petrobras, e continuamente aperfeiçoado no laboratório da UFSC.

Figura 6 - Medidor de tensões residuais - primeira versão de bancada - 1993
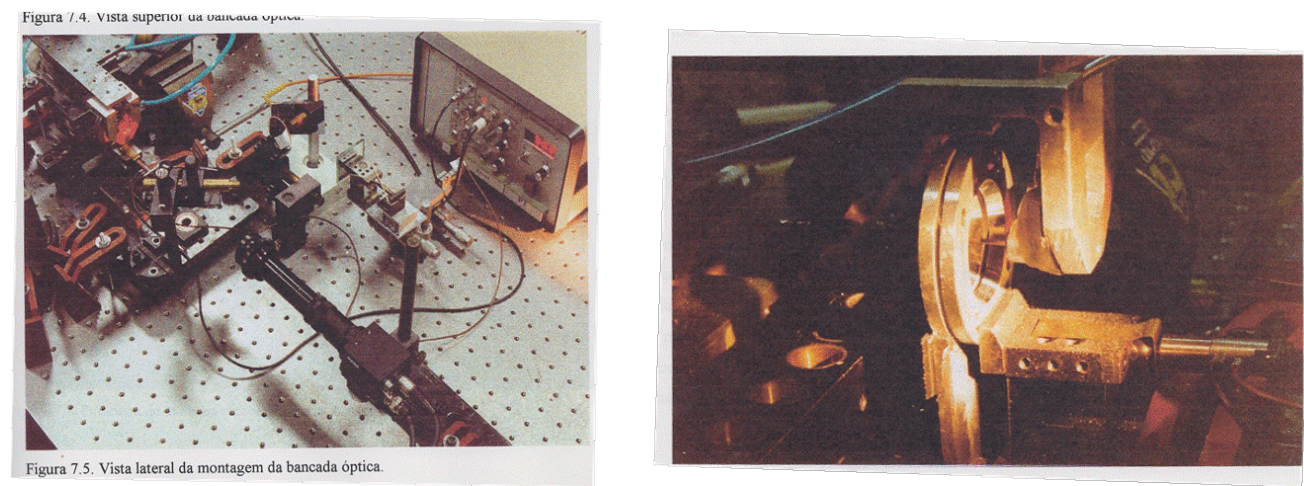

Fonte: (AZEVEDO, 2016) a partir de (JUNIOR, 2016)

Figura 7 - Medidor de tensões residuais - primeiras versões semi-portáteis - 1996
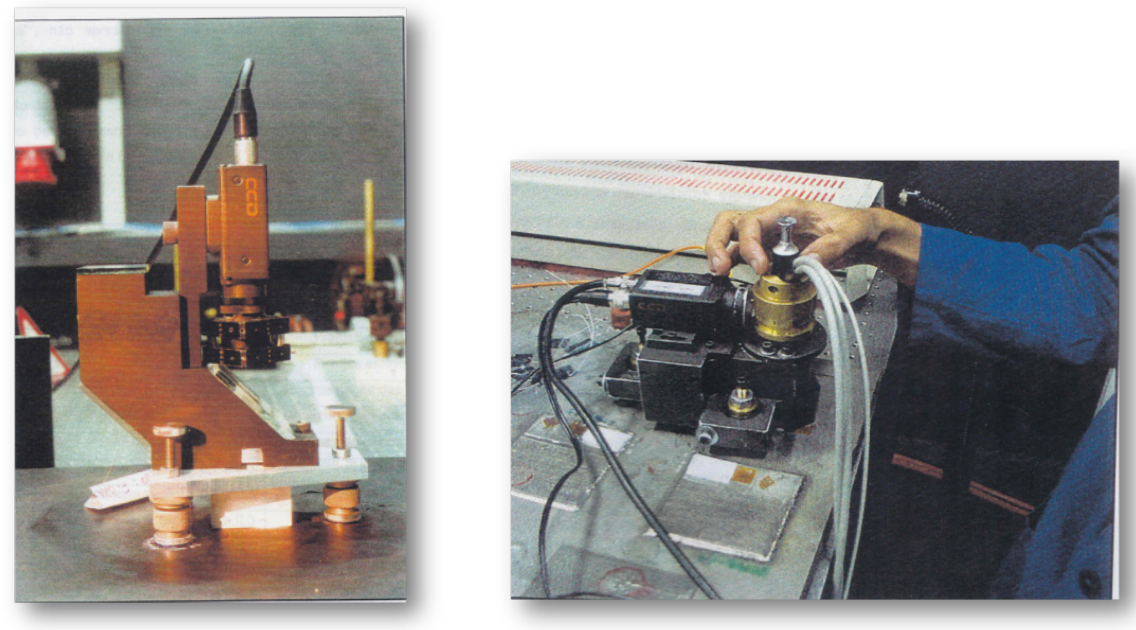

Fonte: (AZEVEDO, 2016) a partir de (JUNIOR, 2016) 
Figura 8 - Medidor de tensões residuais, $1^{\text {a }}$. $2^{\mathrm{a}}$ e $3^{\mathrm{a}}$ versão portáteis -1999

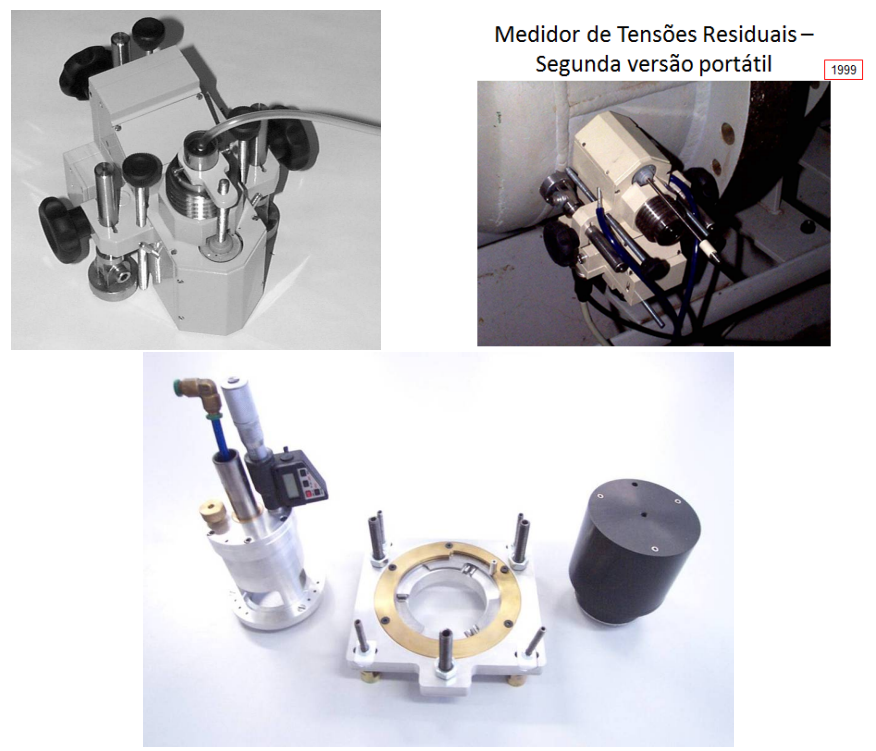

Fonte: (AZEVEDO, 2016) a partir de (JUNIOR, 2016)

Figura 9 - Melhoria das imagens (da esquerda para direita: 2003, 2006, 2009, 2012)
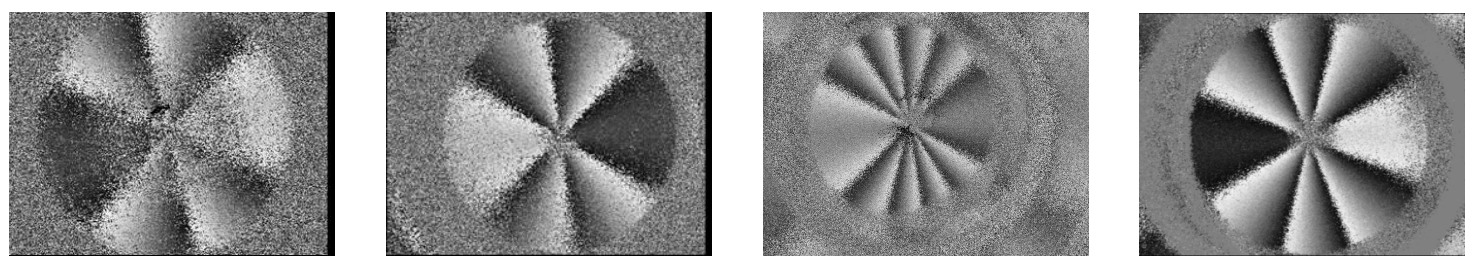

Fonte: (AZEVEDO, 2016) a partir de (JUNIOR, 2016)

Nestes termos, os avanços tecnológicos provenientes da parceria UFSC e Petrobrás caminham em linha com os apontamentos de Suzigan e Furtado Suzigan e Furtado (2006), de que o desenvolvimento econômico e social não é decorrente apenas da acumulação de capital físico e humano, mas, do aprendizado de tecnologias novas e a maneira de compreendê-la a ponto de dominá-las. Esse domínio possibilita a evolução da trajetória do progresso técnico, expressos pelos resultados positivos das inovações realizadas. Atribuise a tal ocorrência, a grande importância dos processos de interação U-E, que propiciam parcerias duradouras resultando na evolução tecnológica, e, contribuindo assim para o desenvolvimento econômico e social.

Econômica-Niterói, v. 20, n. 2, p. 59-84. Dezembro, 2018 
Figura $10-1^{\mathrm{a}}$ versão com óptica difrativa e uso em campo
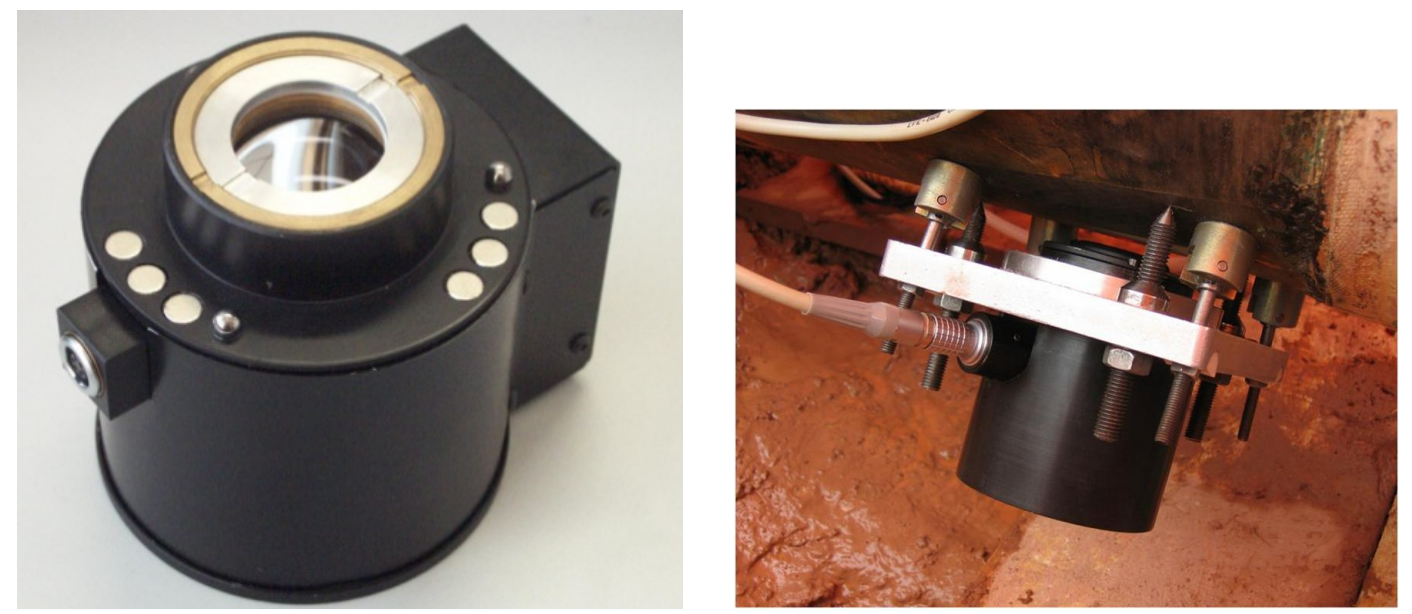

Fonte: (AZEVEDO, 2016) a partir de (JUNIOR, 2016)

Figura $11-1^{\circ}$ Dispositivo portátil robusto

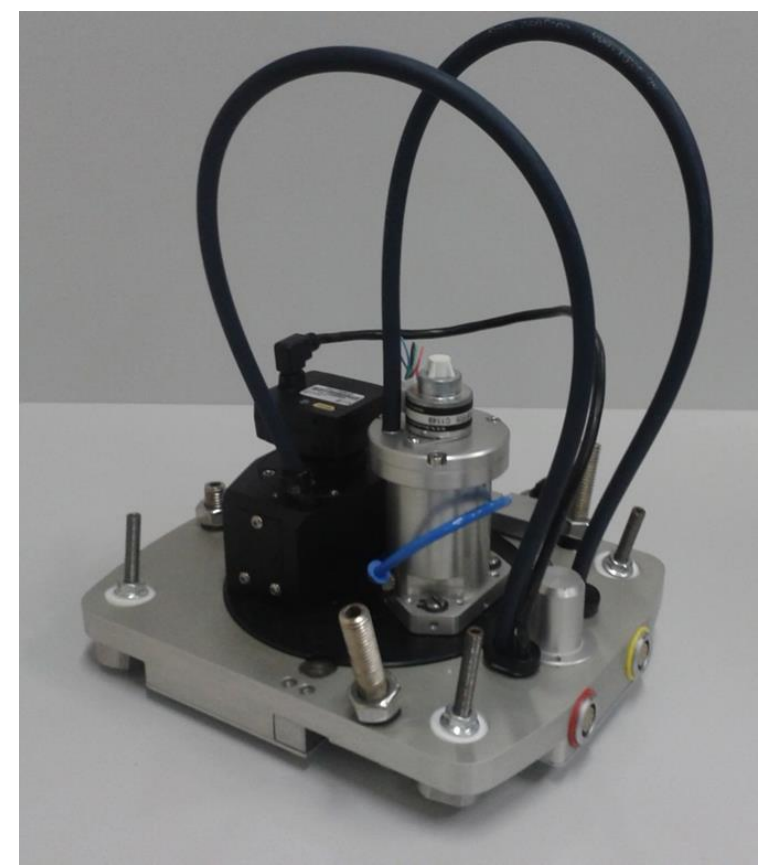

Fonte: (AZEVEDO, 2016) a partir de (JUNIOR, 2016)

\section{Conclusões}

A compreensão do fenômeno da interação U-E é importante, pois estas relações de parceria são basilares do Sistema Nacional de Inovação, na medida em que se gera um 
fluxo bidirecional de trocas de conhecimento e aproxima-se a academia do setor produtivo, resultando na geração de processos inovativos. Os avanços tecnológicos decorrentes desta interação trazem benefícios que extrapolam a própria parceria, pois na Universidade há um ganho de infraestrutura, de recursos, de formação de pesquisadores e de provocações científicas provenientes de demandas do setor produtivo, na empresa agrega-se o conhecimento tecnológico que incitam questionamentos para novas pesquisas, e, por fim, estas relações contribuem para o desenvolvimento do país.

Diante do exposto, buscou-se por meio deste estudo avaliar os esforços de capacitação tecnológica decorrentes da interação da Petrobras, uma transacional pública situada no setor de petróleo e gás, com a Universidade Federal de Santa Catarina, através dos laboratórios de pesquisa da Universidade. Para tanto, procurou-se realizar uma contextualização das atividades de pesquisa realizadas pelos principais laboratórios da UFSC, os quais respondem por mais de $50 \%$ das parcerias realizadas com a Petrobras, e na sequência foram apresentadas o desenvolvimento de duas tecnologias selecionadas, as quais são decorrentes deste processo de interação.

A pesquisa evidenciou que a interação U-E é essencial no setor no qual está situada a empresa, por se tratar de um setor baseado em ciência, no qual o conhecimento é peçachave. Assim, esta parceria da Petrobras com a UFSC é marcada por uma trajetória histórica no que concerne ao desenvolvimento tecnológico, e que propiciou às parcerias o reconhecimento em nível internacional por estas tecnologias de fronteira. A empresa possibilitou a criação e manutenção de infraestrutura de ponta, além do apoio contínuo por meio de diferentes projetos, e na Universidade verificou-se o reconhecimento deste suporte concedido pela empresa e da relevância do apoio a projetos de longo prazo para o desenvolvimento de importantes tecnologias, como as aqui apresentadas, a rocha digital e a avaliação do carregamento em dutos a partir das tensões residuais.

Esta pesquisa, embora limitada a investigar a interação da UFSC e Petrobras, retrata a importância da compreensão do fenômeno da interação U-E no contexto brasileiro, especialmente em virtude do potencial que esta parceria tem no que tange ao desenvolvimento da inovação e consequentemente no desenvolvimento social e econômico do país. Além disso, o presente estudo instiga novas questões para investigação, como, por exemplo, a análise dos esforços de capacitação tecnológica em outras Universidades públicas em parceria com transnacionais públicas que interagem por longo período de tempo e desenvolvem inovação em diferentes setores da economia brasileira. Sugere-se ainda a utilização do aporte teórico institucionalista-evolucionário para a compreensão em profundidade do fenômeno da interação U-E.

\begin{abstract}
The interaction between university and company (U-C) ischaracterized as an important interinstitutional arrangement in the National Innovation System (SNI), because it enables the generation of innovative processes. Thus, the aim of this study is to evaluate the technological capacity building
\end{abstract}

Econômica-Niterói, v. 20, n. 2, p. 59-84. Dezembro, 2018 
efforts resulting from company Brazilian Oil S.A. (Petrobras) interaction with Federal University of Santa Catarina (UFSC). For that, a theoretical-empirical, descriptive, bibliographic and case study was carriedout, whose approach it was qualitative. The interviews wereconducted with the research coordinators of the university's laboratories, and it wascarried out the consultation of projects in partnerships and institutional websites of University and company. It was evidenced that the partnership between UFSC and Petrobras is marked by a historical trajectory with regard to technological development, and that allowed the partnerships to be recognized at the international level by these frontier technologies, such as those presented in this study, digital rock and assessment of pipeline loading from residual tensions.

Keywords: University-company interaction; UFSC; Petrobras; technological development.

JEL: NI

\section{Referências bibliográficas}

ALVIM, P. C. R. C. Cooperação universidade-empresa: da intenção à realidade. In: Interação universidade-empresa. Brasília: Instituto Brasileiro de Informação em Ciência e Tecnologia, 1998. p. 99-125.

AREND, M. 50 anos de industrialização do Brasil (1955-2005) : uma análise evolucionária. Tese (Doutorado) - UFRGS, 2009. Disponível em: <https: //lume.ufrgs.br/handle/10183/16408>.

AZEVEDO, P. A interação UFSC e Petrobras para o desenvolvimento inovativo sob a óptica institucionalista-evolucionária. 508 p. Tese (Doutorado) — Universidade Federal de Santa Catarina, 2016. Disponível em: <https://repositorio.ufsc.br/handle/123456789/ 169206>.

BERNARDES, A. T.; ALBUQUERQUE, E. d. M. e. Cross-over, thresholds, and interactions between science and technology: lessons for less-developed countries. Research Policy, Elsevier, v. 32, n. 5, p. 865-885, 2003. Disponível em: $<$ https://ideas.repec.org/a/eee/respol/v32y2003i5p865-885.html>.

BONACCORSI, A.; PICCALUGA, A. A theoretical framework for the evaluation of university-industry relationships. $R \& D$ Management, Wiley/Blackwell (10.1111), v. 24, n. 3, p. 229-247, 7 1994. ISSN 0033-6807. Disponível em: <http: //doi.wiley.com/10.1111/j.1467-9310.1994.tb00876.x>.

CUNHA, N. d. MECANISMOS DE INTERAÇÃO UNIVERSIDADE-EMPRESA E SEUS AGENTES: O GATEKEEPER EO AGENTE UNIVERSITÁRIO DE 
INTERAÇÃO. REAd-Revista Eletrônica de Administração, v. 5, n. 1, 1999. Disponível

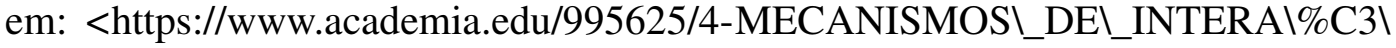

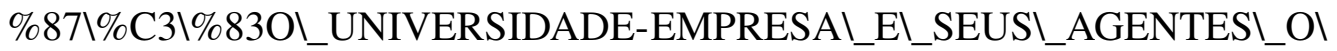

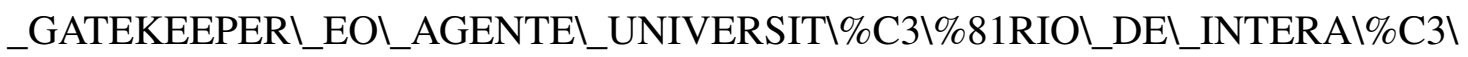
$\% 87 \backslash \% \mathrm{C} 3 \backslash \% 83 \mathrm{O}>$.

DOSI, G. . Mudanca tecnica e transformacao industrial a teoria e uma aplicacao a industria dos semicondutores. Editora Unicamp, 2006. ISBN 9788526807334. Disponível em: $<$ https://www.wook.pt/livro/mudanca-tecnica-e-transformacao-industrial-giovanni-dosi/ 199817>.

DOSI, G. Sources, Procedures, and Microeconomic Effects of Innovation. Journal of Economic Literature, v. 26, n. 3, p. 1120-1171, 1988. Disponível em: $<$ http://www.jstor.org/stable/2726526>.

D'ESTE, P.; PATEL, P. University-industry linkages in the UK: What are the factors underlying the variety of interactions with industry? Research Policy, v. 36, n. 9, p. 1295-1313, 11 2007. ISSN 00487333. Disponível em: <http://linkinghub.elsevier.com/retrieve/pii/S0048733307001199>.

EDQUIST, C. Systems of innovation : technologies, institutions, and organizations. Pinter, 1997. 432 p. ISBN 1855674521. Disponível em: <https://catalogue.nla.gov.au/ Record/1490882>.

EDQUIST, C. The Systems of Innovation Approach and Innovation Policy: An account of the state of the art. In: DRUID Conference. Aalborg: [s.n.], 2001.

EDQUIST, C. Reflections on the systems of innovation approach. Science and Public Policy, Oxford University Press, v. 31, n. 6, p. 485-489, 12 2004. ISSN 03023427. Disponível em: <https://academic.oup.com/spp/article-lookup/doi/10.3152/ $147154304781779741>$.

FERNANDES, A. C. et al. Academy-industry links in Brazil: evidence about channels and benefits for firms and researchers. Science and Public Policy, Oxford University Press, v. 37, n. 7, p. 485-498, 8 2010. Disponível em: $<$ https://academic.oup.com/spp/article-lookup/doi/10.3152/030234210X512016>.

FREEMAN, C. The 'National System of Innovation' in historical perspective. Cambridge Journal of Economics, Oxford University Press, v. 19, n. 1, p. 5-24, 2 1995. ISSN 1464-3545. Disponível em: <https://academic.oup.com/cje/article/19/1/5/1708372/ The-National-System-of-Innovation-in-historical $>$.

GUIMARÃES, R. R. R.; PLONSKI, G. A. Diferentes estratégias de instituições de P\&amp;D públicas na interação com a indústria. In: Anais do Simpósio de Gestão da Inovação Tecnológica. Curitiba: [s.n.], 2004.

Econômica-Niterói, v. 20, n. 2, p. 59-84. Dezembro, 2018 
JUNIOR, A. A. G. Apresentacao do projeto tensoes e deformacoes. Florianópolis, 2016.

KERN, V. Informação e conhecimento em plataformas de governo Eletrônico. In:

Governo eletrônico e inclusão digital. Florianópolis: Fundação Boiteux, 2009. p. 63-71.

KRETZER, J. Sistemas de inovação: as contribuições das abordagens nacionais e regionais ou locais. Ensaios FEE, v. 30, n. 2, p. 863-892, 2009. Disponível em: $<$ https://revistas.fee.tche.br/index.php/ensaios/article/view/2344>.

LABMETRO. Laboratório de metrologia e automação. Disponível em: <www.labmetro. ufsc.br>.

LABTUCAL. Laboratório de tubos de calor. 2017. Disponível em: <http: //www.lepten.ufsc.br/pesquisa/tucal/tucal.html>.

LASTRES, H. M. M.; CASSIOLATO, J. E. Glossário de arranjos e sistemas produtivos e inovativos locais. Arranjos produtivos locais: uma nova estratégia de ação para o SEBRAE. Vitória: SEBRAE, 2005. Disponível em: <http: //www.ijsn.es.gov.br/bibliotecaonline/Record/330978>.

LMPT. Laboratório de meios porosos e propriedades termofísicas. Disponível em: $<$ http://www.lmpt.ufsc.br>.

LUNDVALL, B.-A. National systems of innovation : toward a theory of innovation and interactive learning. Anthem, 1992. 388 p. ISBN 9780857286741. Disponível em: <https://www.jstor.org/stable/j.ctt1gxp7cs>.

LUNDVALL, B.- Innovation System Research - Where it came from and where it might go - Globelics. In: LUNDVALL, B.- (Ed.). National systems of innovation. London: Anthem Press, 2010. p. 317-351. Disponível em: <http://www.globelics.org/article/ innovation-system-research-where-it-came-from-and-where-it-might-go/>.

MACULAN, A.-M. Capacitação tecnológica e inovação nas empresas brasileiras: balanço e perspectivas. Cadernos EBAPE.BR, v. 3, n. spe, p. 01-18, 2005. ISSN 1679-3951. Disponível em: <http://www.scielo.br/scielo.php?script=scil_arttext\&pid= S1679-39512005000500007\&lng=pt\&tlng=pt $>$.

MALERBA, F. Sectoral Systems: How and Why Innovation Differs across Sectors. In: FAGERBERG, J.; MOWERY, D. C.; NELSON, R. R. (Ed.). The Oxford handbook of innovation. Oxford: Oxford University Press, 2007. p. 380-406. Disponível em: <http://oxfordhandbooks.com/view/10.1093/oxfordhb/9780199286805.001.0001/ oxfordhb-9780199286805-e-14>.

MEYER-KRAHMER, F.; SCHMOCH, U. Science-based technologies: university-industry interactions in four fields. Research Policy, 
v. 27, n. 8, p. 835-851, 12 1998. ISSN 00487333. Disponível em: <http://linkinghub.elsevier.com/retrieve/pii/S0048733398000948>.

NIOSI, J. E.; Niosi; Jorge. Research policy. Research Policy, Elsevier Science Publishers B.V. (North-Holland), v. 31, n. 2, p. 291-302, 2002. Disponível em: <https://econpapers. repec.org/article/eeerespol/v\_3a31\_3ay\_3a2002\_3ail_3a2\_3ap\_3a291-302.htm>.

OLIVEIRA, J. M.; FIGUEIREDO, C. O. Caracterização dos investimentos em P\&amp;D da PETROBRAS. In: TURCHI, L.; NEGRI, F. D.; NEGRI, J. A. D. (Ed.). Impactos tecnológicos das parcerias da PETROBRAS com universidades centros de pesquisa e firmas brasileiras. Brasília: IPEA, 2013.

PEREZ, C. Revoluciones tecnológicas y capital financiero: la dinámica de las grandes burbujas financieras y las épocas de bonanza. México: Siglo XXI, 2004.

PETROBRAS. Relatório de Tecnologia Petrobras 2014. [S.1.], 2017. Disponível em: <http://www.petrobras.com.br/pt/nossas-atividades/tecnologia-e-inovacao/ relatorio-de-tecnologia/>.

POLO. Laboratório de pesquisa em refrigeração e termofísica. 2017. Disponível em: $<$ http://www.polo.ufsc.br/projetos.html>.

RAPINI, M. E. A. A interação entre empresas industriais e universidades em Minas Gerais: investigando uma dimensão estratégica do sistema estadual de inovação. In: Encontro Nacional Anpec. [S.1.]: Anpec, 2008.

REMAS. Núcleo ressacada de pesquisa em meio ambiente. 2017. Disponível em: $<$ http://rema.ufsc.br/pesquisas/>.

SEGATTO, A. P.; SBRAGIA, A. Cooperação universidade-empresa: um estudo exploratório. In: Anais de XIX Simpósio de Gestão da Inovação Tecnológica. [S.1.: s.n.], 1998.

SINMEC. Laboratório de simulação numérica em mecânica dos fluídos e transferência de calor. Disponível em: <http://www.sinmec.ufsc.br/site/projetos.php>.

SUZIGAN, W.; ALBUQUERQUE, E. M.; Cario. S. A. F. Introdução. In: SUZIGAN, W.; ALBUQUERQUE, E. M.; Cario. S. A. F. (Ed.). Em busca da inovação: interação universidade-empresa no Brasil. Belo Horizonte: Autêntica Editora, 2011.

SUZIGAN, W.; FURTADO, J. Politica industrial e desenvolvimento. Revista de Economia Politica, v. 26, n. 2, p. 163-185, 2006.

TRIVIÑOS, A. N. S. Introdução à pesquisa em ciências sociais: a pesquisa qualitativa em educação. São Paulo: Atlas, 2006. 